\title{
Effect of neoadjuvant chemoradiation and postoperative radiotherapy on expression of heat shock protein 70 (HSP70) in head and neck vessels
}

\author{
Frank Tavassol", Horst Kokemüller, Rüdiger Zimmerer, Nils-Claudius Gellrich and André Eckardt
}

\begin{abstract}
Background: Preoperative radiotherapy and chemotherapy in patients with head and neck cancer result in changes to the vessels that are used to construct microsurgical anastomoses. The aim of the study was to investigate quantitative changes and HSP70 expression of irradiated neck recipient vessels and transplant vessels used for microsurgical anastomoses.

Methods: Of 20 patients included in this study five patients received neoadjuvant chemoradiation, another five received conventional radiotherapy and 10 patients where treated without previous radiotherapy. During surgical procedure, vessel specimens where obtained by the surgeon. Immunhistochemical staining of HSP70 was performed and quantitative measurement and evaluation of HSP70 was carried out.

Results: Conventional radiation and neoadjuvant chemoradiation revealed in a thickening of the intima layer of recipient vessels. A increased expression of HSP70 could be detected in the media layer of the recipient veins as well as in the transplant veins of patients treated with neoadjuvant chemoradiation. Radiation and chemoradiation decreased the HSP70 expression of the intima layer in recipient arteries. Conventional radiation led to a decrease of HSP70 expression in the media layer of recipient arteries.

Conclusion: Our results showed that anticancer drugs can lead to a thickening of the intima layer of transplant and recipient veins and also increase the HSP70 expression in the media layer of the recipient vessels. In contrast, conventional radiation decreased the HSP70 expression in the intima layer of arteries and the media layer of recipient arteries and veins. Comparing these results with wall thickness, it was concluded, that high levels of HSP70 may prevent the intima layer of arteries and the media layer of vein from thickening.
\end{abstract}

\section{Background}

Irradiation and vessels

The therapy of patients suffering from oral cancer could be recently improved by utilization of multimodal interdisciplinary regimes using a combination of surgery, chemo- and radiotherapy [1,2]. Extensive tissue defects following ablative tumor therapy do require adequate and functional reconstruction regardless of whether the patient received preoperative irradiation or not. During the last 20 years, the free vascularised tissue transfer became to be the "criterion standard" for reconstruction in head and neck cancers [3-6]. Large patient series with

\footnotetext{
* Correspondence: Tavassol.Frank@mh-hannover.de

Department of Oral and Maxillofacial Surgery, Hannover Medical School,
} Hanover, Germany

(c) 2011 Tavassol et al; licensee BioMed Central Ltd. This is an Open Access article distributed under the terms of the Creative Commons Attribution License (http://creativecommons.org/licenses/by/2.0), which permits unrestricted use, distribution, and reproduction in any medium, provided the original work is properly cited. struction have been reported by many authors and demonstrated today's role as principal reconstructive procedure [5-10]. Since Guelinckx (1984) we know that irradiation of the recipient vessels in head and neck free flaps is leading to morphological changes [11]. Following studies confirm these results [12-14]. Different authors conclude, thus, although success is certainly possible when irradiated vessels are used for flap revascularization, there may be an increased risk of thrombosis, particularly in the head and neck $[15,16]$. Reviewing the current literature is leading to a different success rate of free flaps in irradiated patients ranging from $88 \%$ to nearly $100 \%$ [17-22]. Regarding the histological findings after irradiation, qualitative changes of the vessels such as hyalinosis of the intima and the media are described in 
literature [11,23]. Schultze-Mosgau et al. (2002) could show qualitative and quantitative histological changes to the recipient arteries, but not to the recipient veins following irradiation with 60-70 Gy. In contrast, neoadjuvant chemoradiation did not show changes to the recipient vessels [14].

\section{Heat shock proteins (HSP)}

HSP are found in all organisms and all cell types. They are the most phylogenetically conserved proteins known with respect to both structure and function [24]. Usually, HSP are expressed at low levels, and under normal physiological conditions, many members of the HSP family are involved in protein synthesis. When a cell is stressed, oligomeric complexes disassemble and polypeptides unfold. Under these conditions, the role of HSP is to reverse such changes and, if refolding becomes impossible, to potentially speed up the removal of such denatured proteins. Expression of HSP is induced even under nonstress conditions, including those of the cell cycle, development, and differentiation [24-26]. Regarding the literature, even radiation could induce stress proteins in vitro [27]. Hurwitz et al. (2010) could show that radiation therapy induces expression of HSP70 in patients with prostate cancer [28]. Furthermore, the expression of heat shock proteins is induced by anticancer drugs such cisplatin $[29,30]$.

\section{Aim of the study}

The aim of the study was to investigate quantitative changes and HSP70 expression of irradiated neck recipient vessels and transplant vessels used for microsurgical anastomoses in free flaps in patients undergoing preoperative radiotherapy or neoadjuvant chemoradiation. The second aspect was to find out if HSP 70 might protect the transplant and recipient vessels.

\section{Methods}

\section{Patients}

The ethical approval was given by the local ethical committee. Of 20 patients included in this study (March 2004 - October 2006), 10 patients where treated without previous radiotherapy (group 1), five patients received conventional radiotherapy (59.4 - 72 Gy) (group 2) at least 22 months before surgery and another five patients received neoadjuvant chemoradiation 6 weeks before surgery (group 3 , Table 1 ). The neoadjuvant chemoradiation protocol included cisplatin $12.5 \mathrm{mg} / \mathrm{m}^{2}$ plus 40 Gy radiation or paclitaxel $40 \mathrm{mg} / \mathrm{m}^{2} /$ carboplatin AUC 1.5 plus 40 Gy radiation [1,2]. During surgical procedure, 5-10 mm long vessel specimens where obtained by the surgeon. In each case a transplant artery and transplant vein from the raised flap and a recipient artery (superior thyroid or facial artery) and a recipient vein (facial vein) from the neck were achieved.

\section{Immunhistochemistry}

Serial 3-mm sections were deparaffinized, rehydrated, washed and, treated with a solution of $2 \%$ horse serum, $0.1 \%$ bovine serum albumin (Sigma Corporation, Steinheim, Germany), and $0.1 \%$ sodium acid in $150 \mathrm{mmol} / \mathrm{l}$ phosphate-buffered saline (PBS; pH 7.2) for $15 \mathrm{~min}$ to block nonspecific antibody-binding. A polyclonal rabbit anti-HSP70 antibody (Dako, Carpinteria, CA, USA), specific to HSP from Escherichia coli, which shares more than $48 \%$ sequence homology with mammalian HSP70 was the first layer. The optimal dilution of anti-HSP antibody (1:250) was determined by titration. The selected sections were incubated with this antibody for $120 \mathrm{~min}$ at room temperature (RT). The second layer, a biotin-conjugated goat antirabbit immunoglobulin (Oncogene, San Diego, CA USA) diluted 1:200 in PBS was incubated for $30 \mathrm{~min}$ at RT. The third layer was an avidin-biotin-horseradish peroxidase complex (Dako) diluted 1:50 in PBS. Incubation was, as before, $30 \mathrm{~min}$ at RT. Sections were washed for $10 \mathrm{~min}$ in 2 changes of PBS between each layer. The color reaction was developed with a solution consisting of 0.05\% 3,30- diaminobenzidine tetrahydrochloride (Sigma, St Louis, MO, USA), 0.03\% nickel chloride (Sigma), and $0.01 \%$ hydrogen peroxide in $48 \mathrm{mmol} / \mathrm{l}$ Tris-HCL, $\mathrm{pH} 7.6$ (Sigma). Counterstaining was carried out with Mayer's hematoxylin $[24,26]$.

\section{Quantitative evaluation}

For quantitative histomorphometric analysis, cross-sections were obtained from the middle third of the vessels and analyzed with the image processing and analysis program analysis $3.1^{\circledR}$ (Soft Imaging System, Münster, Germany). The measurement included the vessel wall thickness differed by the intima and the media and was carried out three times by two examiners. The mean values thus obtained were used for the following analysis.

\section{Evaluation of HSP 70 expression}

Light microscopy and analysis $3.1^{\circledR}$, an image processing and analysis program, were used for evaluating HSP70 expression. Respectively the intima, media or adventitia region was defined as the region of interest (ROI) and the percentage of HSP70-positive staining was analyzed [26].

\section{Statistical analysis}

Statistical analysis was performed on a SPSS 18 statistical package. The specimens were compared for differences in percentage of HSP 70 staining and thickness of 
Table 1 Clinical data from patients included in the study

\begin{tabular}{|c|c|c|c|c|c|c|c|c|c|}
\hline $\begin{array}{l}\text { case } \\
\text { No. }\end{array}$ & age & gender & pTNM & $\begin{array}{l}\text { radiation } \\
\text { dose (Gy) }\end{array}$ & $\begin{array}{l}\text { time between } \\
\text { radiation and } \\
\text { surgery (months) }\end{array}$ & donor site & chemotherapy & $\begin{array}{c}\text { neo adjuvant } \\
\text { therapy }\end{array}$ & smoker \\
\hline 1 & 49 & $\mathrm{~m}$ & pT2 pN1 & no radiation & -—— & radial forearm flap & - - & & yes \\
\hline 2 & 74 & $\mathrm{~m}$ & pT4a pN2b & no radiation & -二- & radial forearm flap & - - & & no \\
\hline 3 & 51 & $\mathrm{~m}$ & pT4a pNO & no radiation & -—-— & fibula flap & -— & & yes \\
\hline 4 & 84 & $f$ & pT2 pN0 & no radiation & -——- & radial forearm flap & - - & & no \\
\hline 5 & 69 & f & pT4 pN2 & no radiation & -—— & radial forearm flap & - - & & no \\
\hline 6 & 46 & $\mathrm{~m}$ & pT2 pN0 & no radiation & -—- & radial forearm flap & -—- & & yes \\
\hline 7 & 65 & $\mathrm{~m}$ & pT4 pN0 & no radiation & -— & latissimus dorsi flap & - - & & yes \\
\hline 8 & 44 & $\mathrm{~m}$ & pT1 pNo & no radiation & -—— & radial forearm flap & & & yes \\
\hline 9 & 64 & $\mathrm{~m}$ & pT1 pNo & no radiation & -—- & radial forearm flap & & & yes \\
\hline 10 & 46 & $\mathrm{~m}$ & pT2 pN1 & no radiation & - - & lateral arm flap & - - & & no \\
\hline 11 & 55 & f & ypT1 pNo & 40 & 1,5 & radial forearm flap & carboplatin + taxol & yes & yes \\
\hline 12 & 48 & $\mathrm{~m}$ & ypT1 pNo & 40 & 1,5 & latissimus dorsi flap & carboplatin + taxol & yes & yes \\
\hline 13 & 43 & $\mathrm{~m}$ & урT1 ypN1 & 40 & 1,5 & radial forearm flap & cisplatin/5-FU & yes & yes \\
\hline 14 & 55 & $\mathrm{~m}$ & ypT1 ypN0 & 40 & 1,5 & radial forearm flap & carboplatin + taxol & yes & yes \\
\hline 15 & 57 & $\mathrm{~m}$ & ypT1 ypN1 & 40 & 1,5 & latissimus dorsi flap & cisplatin/5-FU & yes & yes \\
\hline 16 & 57 & $\mathrm{~m}$ & pT4 pN3 & 60 & 108 & radial forearm flap & - & & yes \\
\hline 17 & 64 & $\mathrm{~m}$ & pT4 pN1 & 60 & 120 & latissimus dorsi flap & - & & no \\
\hline 18 & 30 & $\mathrm{~m}$ & pT2 pN2b & 59.4 & 22 & latissimus dorsi flap & - & & no \\
\hline 19 & 51 & $\mathrm{~m}$ & pT4 N2b & 61.2 & 20 & latissimus dorsi flap & - & & yes \\
\hline 20 & 58 & $\mathrm{~m}$ & pT4 N2a & 72 & 81 & radial forearm flap & - & & no \\
\hline
\end{tabular}

the intima and media part of the vessels respectively. One way repeated measures Analysis of Variance was used to detect differences and correlations at $\mathrm{p}$ values less than 0.05 .

\section{Results}

\section{Clinical data}

There where three women (15\%) and 17 men included in this study. The mean age of all patients was 55.5 years (range 30 to 84, median 55, SEM 3.69). The mean age of group 1 (no irradiation) was 59.2 years (median 57.5), the mean of group 2 (conventional irradiation, 59.4-72 Gy) was 52 years (median 57) and of group 3 (neoadjuvant chemoradiation, 40 Gy) 51.6 years (median 55 ). The mean duration between conventional radiation (group2) and surgical treatment was 70.2 months (median 80). Thirteen patients stated to be smokers (65\%). Reconstruction was performed by using the radial forearm flap in 12 cases (60\%), latissimus dorsi flap in six cases and each one by fibula flap and lateral arm flap (5\% each, table 1). All flaps were successful.

\section{Vessel wall thickness}

The results of the vessel wall thickness are summarized in Figure 1A-D and table 2. The wall thickness of the vessels showed significant thickened intima layer of transplant and recipient veins in group 3 (neoadjuvant chemoradiation, Figure 1A). Conventional radiation (group2) led to thickening of the media layer of the recipient veins (Figure 1B). Regarding the arteries, conventional radiation (group2) and neoadjuvant chemoradiation (group3) revealed in a thickening of the intima layer of recipient vessels (Figure 1C). The media layer of the arteries led to a thickening of the recipient vessel in group3 (neoadjuvant chemoradiation) with a contemporary thinning of the transplant vessels in group2 (conventional radiation) and group3 (neoadjuvant chemoradiation, Figure 1D).

\section{HSP70 expression}

The results of HSP70 expression are presented in Figure 2A-D and table 2. A increased expression of HSP70 could be detected in the media layer of the recipient veins as well as in the transplant veins of patients treated with neoadjuvant chemoradiation (group3) (Figure 2B, Figure $3 \mathrm{~A}+\mathrm{B}$ ). Radiation (group2) and chemoradiation decreased the HSP70 expression of the intima layer in recipient arteries (Figure 2C). Regarding the arteries, an enhancement of HSP70 expression was limited to the media layer of the recipient vessels (group3, Figure 3D). Conventional radiation (group2) led to a decrease of HSP70 expression in the media layer of recipient arteries (Figure 2D, Figure 3C).

\section{Discussion}

Today, free vascularised tissue transfer is the "criterion standard" for tissue reconstruction after ablative tumour 


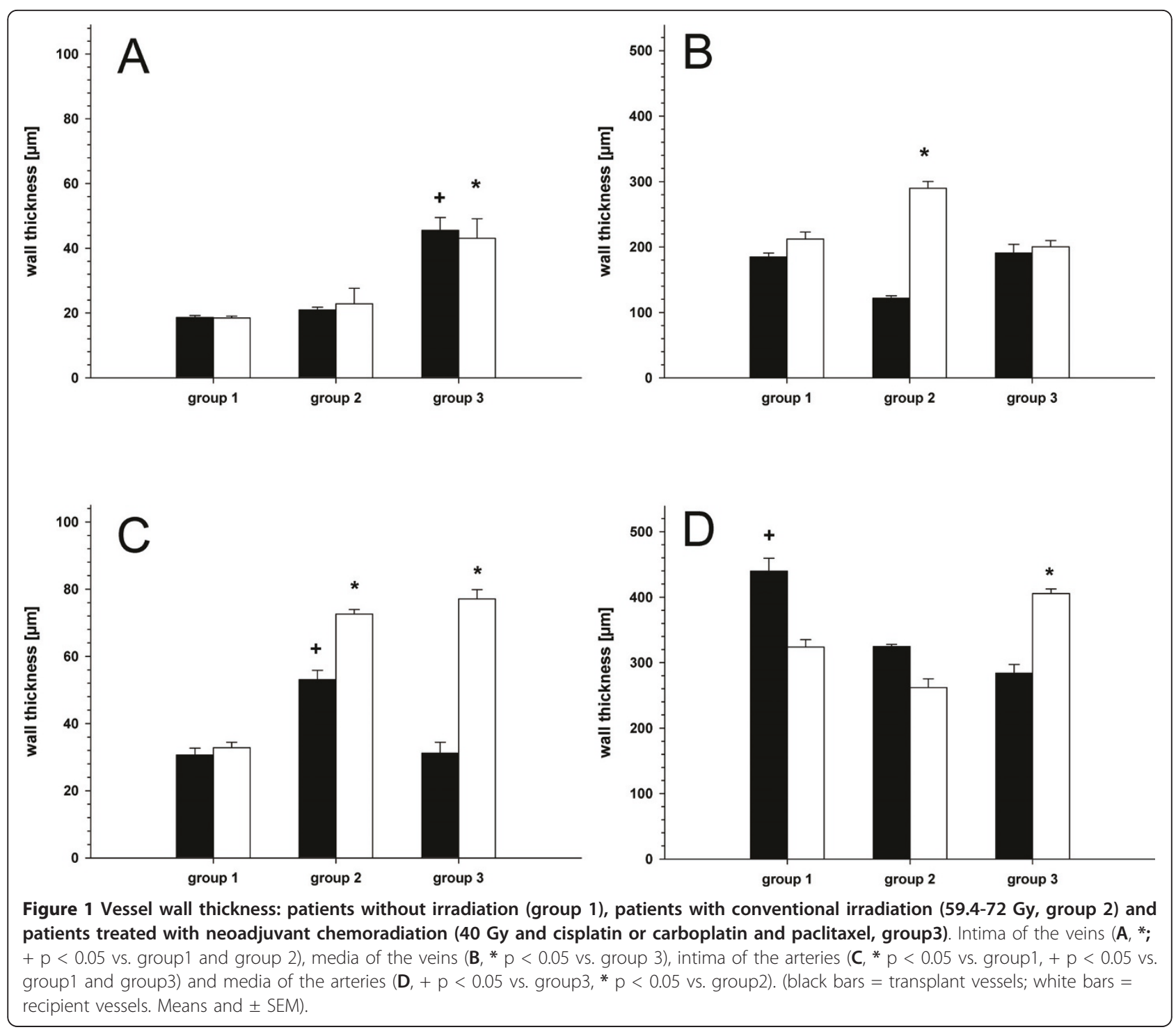

therapy in head and neck oncology [3-6]. Many patients had been treated successfully in the last two decades [5-9]. For successful free tissue transfer, the quality of the transplant and the recipient vessels are desirable. Survival of free flaps is dependent on adequate blood supply. Pre-existing changes in transplant and recipient arteries may cause technical difficulties and must be regarded as additional factors contributing to graft failure $[31,32]$. Histopathologic damage of the recipient vessels in head and neck microsurgery can be caused by different reasons. Arteriosclerotic changes were often seen in patients suffering from head and neck cancer [31]. However, in many cases surgical treatment is not sufficient and adjuvant therapy might be necessary $[1,2]$. In these cases neoadjuvant chemoradiation therapy is used to increase local tumour control and to decrease the incidence of distant metastases. Nevertheless, a preoperative radiation is known to lead to histopathological changes in recipient vessels [12-14,14]. These morphological changes include hyalinosis of the intima and media layer and may increase the risk of thrombosis $[15,16]$. The current literature is describing different success rates of free flaps in irradiated patients ranging from $88 \%$ up to $100 \%$ [17-22]. A previous study from our department could demonstrate that neoadjuvant chemoradiation influenced the outcome of free vascularised tissue transfer while the circumstance if a patient is a smoker or not has no impact to success [6]. Therefore we did not discriminate between smokers and non smokers. To distinguish a possible effect of radiation from the influence of smoking in histomorphometry, we decided to harvest specimens from the transplant. The data of the present study showed different changes of the vessels influenced by preoperative radiation or 
Table 2 Original data (mean \pm SEM) for vessel wall thickness and HSP 70 expression ( $<<0.05$ ): patients without irradiation (group 1), patients with conventional irradiation (59.4-72 Gy, group 2) and patients treated with neoadjuvant chemoradiation (40 Gy and cisplatin or carboplatin and paclitaxel, group3)

\begin{tabular}{|c|c|c|c|c|c|c|}
\hline & group 1 & & group 2 & & group 3 & \\
\hline wall thickness [ $\mu \mathrm{m}]$ & transplant & recipient & transplant & recipient & transplant & recipient \\
\hline intima of veins & $18,6 \pm 0,7$ & $18,5 \pm 0,6$ & $21,0 \pm 0,8$ & $22,8 \pm 4,8$ & $45,6 \pm 4,0$ & $43,1 \pm 6,1$ \\
\hline media of veins & $184,7 \pm 6,3$ & $212,1 \pm 10,6$ & $121,8 \pm 3,9$ & $289,6 \pm 10,5$ & $190,9 \pm 13,2$ & $200,5 \pm 9,3$ \\
\hline intima of arteries & $30,6 \pm 2,0$ & $32,8 \pm 2,8$ & $53,1 \pm 2,8$ & $72,5 \pm 1,4$ & $31,2 \pm 3,2$ & $77,1 \pm 2,8$ \\
\hline media of arteries & $439,8 \pm 19,6$ & $323,6 \pm 11,6$ & $423,9 \pm 3,0$ & $262,0 \pm 13,2$ & $283,8 \pm 13,5$ & $405,5 \pm 7,14$ \\
\hline \multicolumn{7}{|l|}{ HSP70 expression [\%] } \\
\hline intima of veins & $2,04 \pm 0,18$ & $3,06 \pm 0,14$ & $4,22 \pm 0,14$ & $2,54 \pm 0,44$ & $2,27 \pm 0,15$ & $2,92 \pm 0,54$ \\
\hline media of veins & $2,42 \pm 0,22$ & $4,52 \pm 0,21$ & $2,46 \pm 0,18$ & $1,00 \pm 0,05$ & $4,55 \pm 0,55$ & $8,38 \pm 0,94$ \\
\hline intima of arteries & $0,19 \pm 0,01$ & $1,56 \pm 0,24$ & $0,75 \pm 0,23$ & $0,77 \pm 0,09$ & $0,60 \pm 0,12$ & $0,35 \pm 0,23$ \\
\hline media of arteries & $0,51 \pm 0,07$ & $2,41 \pm 0,15$ & $0,14 \pm 0,01$ & $0,32 \pm 0,02$ & $0,81 \pm 0,19$ & $4,41 \pm 0,41$ \\
\hline
\end{tabular}

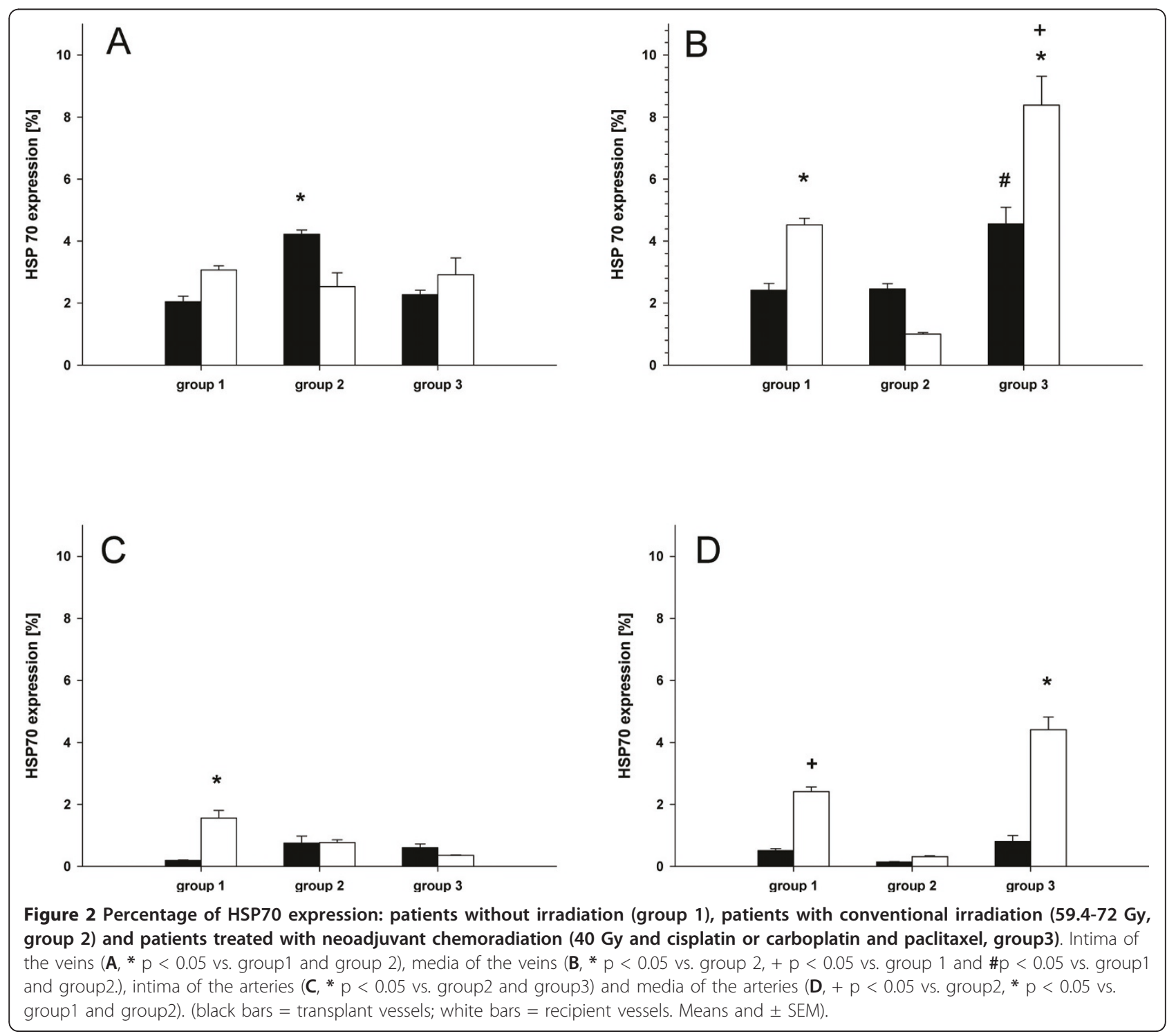



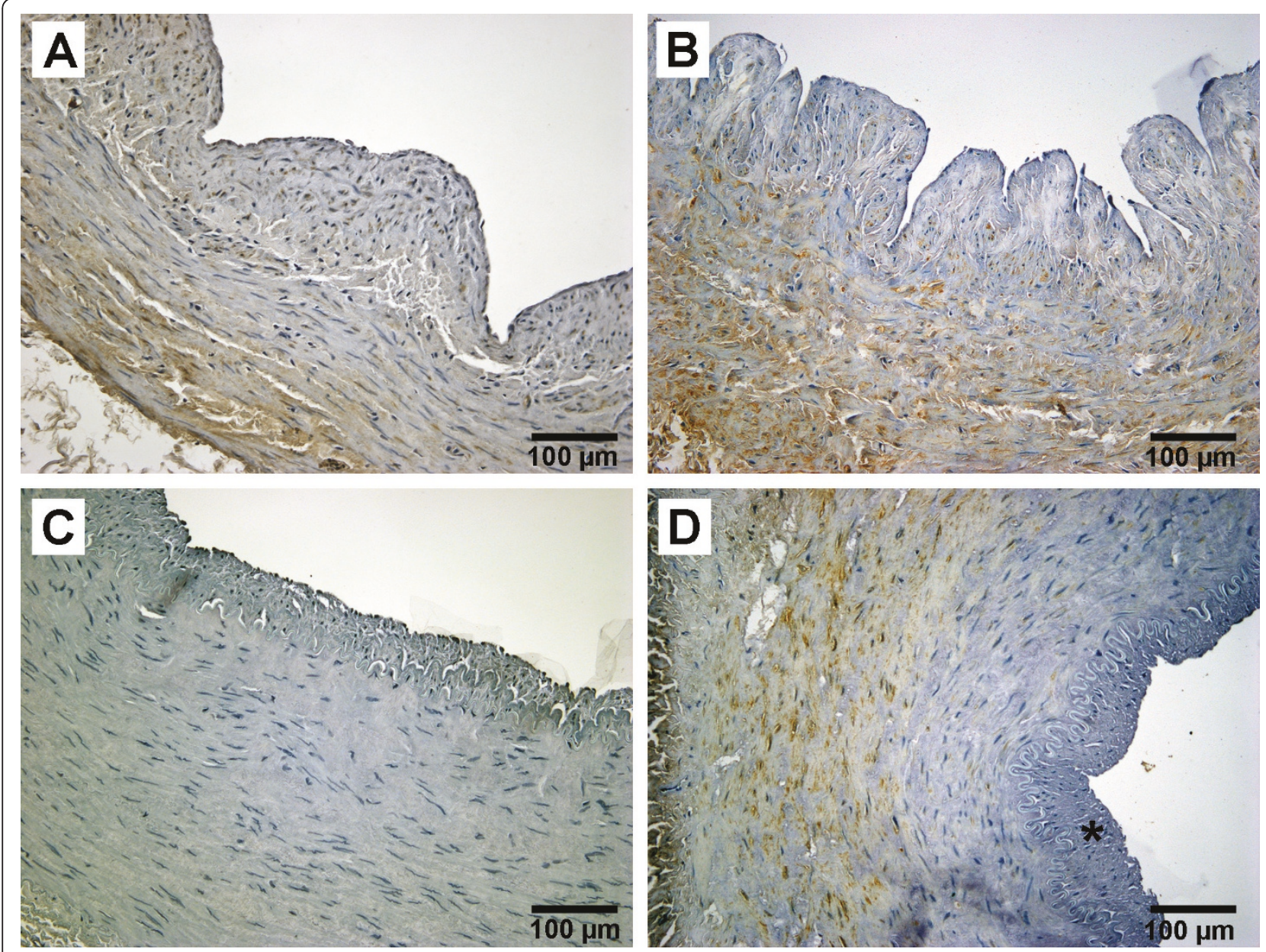

Figure 3 Expression of heat shock protein (HSP) 70 in vessels of a patient treated with neoadjuvant chemoradiation: transplant vein $(A)$, recipient vein $(B)$, transplant artery $(C)$ and recipient artery $(D) .\left(^{*}\right)$ thickened intima;

chemoradiation therapy. A thickened intima layer of the recipient arteries in patients undergoing conventional radiation (group2, 59.4-72 Gy) or neoadjuvant chemoradiation (group3, 40 Gy) could be demonstrated. These findings are partially in contrast to the findings of Schultze-Mosgau et al. (2002), who described changes only after conventional radiation but not after chemoradiation [14]. The study of Schlutze-Mosgau et al. included a total of $93 \%$ smokers while our patient database contains only $60 \%$ smokers. Nevertheless, the chemoradation group (group 3) included 100\% smokers is thus comparable. Another differing result is concerning the veins. We could demonstrate an enlargement of the intima layer of both, the transplant and the recipient vein. This could indicate that anticancer drugs may affect the veins especially considering that conventional radiation has no influence on the intima layer. Only the media layer is influenced by conventional radiation. We think this could be a long-time effect touching the recipient veins.
The second aspect of our study is concerning the HSP70 expression in vessels after radiation or chemoradiation. However, it is known, that radiation therapy or anticancer drugs can induce the expression of HSP70 [27-30,33,34]. Our findings can be concluded in three major results: 1 . chemoradiation increases the HSP70 expression of the media layer in transplant and recipient veins while conventional radiation decreases the expression of HSP70 in the recipient vein. 2 . conventional radiation and chemoradiation decreases HSP70 expression in the intima layer of recipient arteries, and 3. conventional radiation decreases HSP70 expression in the media layer of the recipient artery. Comparing the results of the intima layer of the arteries between HSP70 expression and wall thickness, it seems that low expression of HSP70 correlates with thickened intima layer. This applies to be the same in the media layer of the recipient veins. However, regarding these results it has to be considered that the sample power of this study is low and further study may be helpful to confirm these results. 


\section{Conclusions}

In the present study we could demonstrate, that radiation therapy is affecting the histomorphology of recipient veins of patients suffering from head and neck cancer. Although, there was no failure in our patients, the thickening of the intima layer in recipient arteries may influence success of free vascularised tissue transfer [17-22]. However, anticancer drugs can lead to thickening of the intima layer of transplant and recipient veins. HSP70 expression is decreased by conventional radiation in the intima layer of arteries and the media layer of arteries and veins. Anticancer drugs by contrast increase the HSP70 expression in the media layer of the recipient vessels. Comparing these results with wall thickness, it was concluded, that there might be some coherence between high levels of HSP70 expression and the prevention of thickening of the intima layer of arteries and the media layer of vein from.

\section{Funding}

The article processing charges are funded by the Deutsche Forschungsgemeinschaft (DFG), "Open Acess Publizieren".

\section{Authors' contributions}

FT, HK, RZ, NCG and AE conceived of the study and participated in its design and coordination. FT drafted the manuscript, carried out the immunohistochemistry and performed the statistical analysis. All authors read and approved the final manuscript.

\section{Competing interests}

The authors declare that they have no competing interests.

Received: 10 March 2011 Accepted: 11 July 2011

Published: 11 July 2011

\section{References}

1. Eckardt A, Rades D, Rudat V, Hofele C, Dammer R, Dietl B, Wildfang I, Karstens JH: Prospective phase II study of neoadjuvant radiochemotherapy in advanced operable carcinoma of the mouth cavity. 3-year outcome. Mund Kiefer Gesichtschir 2002, 6:117-21, German.

2. Eckardt A, Wegener G, Karstens JH: [Preoperative radiochemotherapy of advanced resectable cancer of the oral cavity with cisplatin vs paclitaxel/carboplatin. Analysis of two multimodality treatment concepts]. Mund Kiefer Gesichtschir 2006, 10:30-6, German.

3. Harashina T: Analysis of 200 free flaps. Br J Plast Surg 1988, 41:33-6.

4. Schusterman MA, Miller MJ, Rece GP, Kroll S, Marchi M, Goepfert H: A single center's experience with 308 free flaps for repair of head and neck cancer defects. Plast Reconstr Surg 1994, 93:472-8.

5. Eckardt $A$, Fokas $K$ : Microsurgical reconstruction in the head and neck region: an 18-year experience with 500 consecutive cases. J Craniomaxillofac Surg 2003, 31:197-201.

6. Eckardt A, Meyer A, Laas U, Hausamen JE: Reconstruction of defects in the head and neck with free flaps: 20 years experience. $\mathrm{Br} J$ Oral Maxillofac Surg 2007, 45:11-15.

7. Jones NF, Johnson JT, Shestak KC, Myers EN, Swartz WM: Microsurgical reconstruction of the head and neck: interdisciplinary collaboration between head and neck surgeons in 305 cases. Ann Plast Surg 1996, 36:37-43.

8. Amarante J, Reis J, Costa-Ferreira A, Malheiro E, Silva A: Head and neck reconstruction: a review of 117 cases. Eur J Plast Surg 2000, 23:404-412.
9. Rosenthal EL, Dixon SF: Free flap complications: when is enough, enough? Curr Opin Otolaryngol Head Neck Surg 2003, 11:236-239.

10. Nakatsuka T, Harii K, Asato H, Takushima A, Ebihara S, Kimata Y, Yamada A, Ueda K, Ichioka S: Analytic review of 2372 free flap transfers for head and neck reconstruction following cancer resection. $J$ Reconstr Microsurg 2003, 19:363-368.

11. Guelinckx PJ, Boeckx WD, Fossion E, Gruwez JA: Scanning electron microscopy of irradiated recipient blood vessels in head and neck free flaps. Plast Reconstr Surg 1984, 74:217-26.

12. Shibahara T, Schmelzeisen R, Noma H: Histological changes in vessels used for microvascular reconstruction in the head and neck. J Craniomaxillofac Surg 1996, 24:24-28.

13. Schultze-Mosgau S, Erbe M, Keilholz L, Radespiel-Tröger M, Wiltfang J, Minge N, Neukam FW: Histomorphometric analysis of irradiated recipient vessels and transplant vessels of free flaps in patients undergoing reconstruction after ablative surgery. Int J Oral Maxillofac Surg 2000, 29:112-8.

14. Schultze-Mosgau S, Grabenbauer GG, Wehrhan F, Radespiel-Tröger M Wiltfang J, Sauer R, Rödel F: [Histomorphological structural changes of head and neck blood vessels after pre- or postoperative radiotherapy]. Strahlenther Onkol 2002, 178:299-306.

15. Gürlek A, Miller MJ, Amin AA, Evans GR, Reece GP, Baldwin BJ, Schusterman MA, Kroll SS, Robb GL: Reconstruction of complex radiationinduced injuries using free-tissue transfer. J Reconstr Microsurg 1998, 14:337-40

16. Coleman IL: Management of radiation-induced soft-tissue injury to the head and neck. Clin Plast Surg 1993, 20:491-505.

17. Aitasalo $K$, Relander M, Virolainen E: Microvascular free tissue transfers after preoperative irradiation in head and neck reconstructions. Acta Otolaryngol 1997, 529:247-50

18. Aitasalo K, Relander M, Virolainen E: The success rate of free flaps after preoperative irradiation in head and neck reconstruction. Ann Chir Gynaecol 1997, 86:311-7.

19. Evans GR, Schusterman MA, Kroll SS, Miller MJ, Reece GP, Robb GL, Ainslie N: The radial forearm free flap for head and neck reconstruction: a review. Am J Surg 1994, 168:446-50.

20. Jose B, Banis J, Flynn M, Lindberg R, Spanos WJ Jr, Paris K, Rohm J: Irradiation and free tissue transfer in head and neck cancer. Head Neck 1991, 5:213-6.

21. Keidan RD, Kusiak JF: Complications following reconstruction with the pectoralis major myocutaneous flap: the effect of prior radiation therapy. Laryngoscope 1992, 102:521-4.

22. Kroll SS, Schusterman MA, Reece GP, Miller MJ, Evans GR, Robb GL, Baldwin BJ: Choice of flap and incidence of free flap success. Plast Reconstr Surg 1996, 98:459-63.

23. Followill DS, Travis EL: Differential expression of collagen types I and III in consequential and primary fibrosis in irradiated mouse colon. Radiat Res 1995, 144:318-28.

24. Tavassol F, Starke OF, Völker B, Kokemüller H, Eckardt A: Heat-shock protein expression and topical treatment with tacrolimus in oral lichen planus: an immunohistochemical study. Int J Oral Maxillofac Surg 2008, 37:66-9.

25. Morimoto RI: Cells in stress: transcriptional activation of heat shock genes. Science 1993, 259:1409-10.

26. Tavassol F, Starke OF, Kokemüller H, Wegener G, Müller-Tavassol CC, Gellrich NC, Eckardt A: Prognostic significance of heat shock protein 70 (HSP70) in patients with oral cancer. Head Neck Oncol 2011, 23:10.

27. Gehrmann M, Schilling D, Molls M, Multhoff G: Radiation induced stress proteins. Int J Clin Pharmacol Ther 2010, 48:492-3.

28. Hurwitz MD, Kaur P, Nagaraja GM, Bausero MA, Manola J, Asea A: Radiation therapy induces circulating serum $\mathrm{Hsp} 72$ in patients with prostate cancer. Radiother Oncol 2010, 95:350-8.

29. At-Assa S, Porcher JM, Kretz-Remy C, Velarde G, Arrigo AP, Lambre C: Induction of the hsp70 Gene Promoter by Various Anticancer Drugs. Toxicol In Vitro 1999, 13:651-5.

30. García-Berrocal JR, Nevado J, González-García JA, Sánchez-Rodríguez C, Sanz R, Trinidad A, España P, Citores MJ, Ramírez-Camacho R: Heat shock protein 70 and cellular disturbances in cochlear cisplatin ototoxicity model. J Laryngol Otol 2010, 124:599-609.

31. Alberdas $J \mathrm{~L}$, Shibahara T, Noma H: Histopathologic damage to vessels in head and neck microsurgery. J Oral Maxillofac Surg 2003, 61:191-6. 
32. de Bree R, Quak JJ, Kummer JA, Simsek S, Leemans CR: Severe atherosclerosis of the radial artery in a free radial forearm flap precluding its use. Oral Oncol 2004, 40:99-102.

33. Zhou $H$, Kato A, Yasuda $H$, Odamaki M, Itoh H, Hishida A: The induction of heat shock protein-72 attenuates cisplatin-induced acute renal failure in rats. Pflugers Arch 2003, 446:116-24.

34. Jakubowicz-Gil J, Paduch R, Gawron A, Kandefer-Szerszen M: The effect of cisplatin, etoposide and quercetin on Hsp72 expression. Pol J Pathol 2002, 53:133-7.

doi:10.1186/1748-717X-6-81

Cite this article as: Tavassol et al: Effect of neoadjuvant chemoradiation and postoperative radiotherapy on expression of heat shock protein 70 (HSP70) in head and neck vessels. Radiation Oncology 2011 6:81.

\section{Submit your next manuscript to BioMed Central} and take full advantage of:

- Convenient online submission

- Thorough peer review

- No space constraints or color figure charges

- Immediate publication on acceptance

- Inclusion in PubMed, CAS, Scopus and Google Scholar

- Research which is freely available for redistribution

Submit your manuscript at www.biomedcentral.com/submit 